\title{
Can Interactive Learning Improve Learning Experience? A Systematic Review of the Literature
}

\author{
Henrica Brianna Lukita ${ }^{1}$, Yudianto Sujana ${ }^{1}$, Cucuk Wawan Budiyanto ${ }^{1}$ \\ ${ }^{1}$ Information Technology Education, Universitas Sebelas Maret, Jl. Jend. Ahmad Yani \\ 200A Pabelan, Kartasura, Sukoharjo, Indonesia.
}

\begin{abstract}
Interactive learning is a method that encourages students to be active in learning and able to interact with others. The term interactive learning, however, has been associated with the independent learning using computer technology. Interactive learning is used for many benefits in the learning process. This article is a systematic review of dozens of articles in reputable international journals that will describe the types of interactive learning, the application of interactive learning in various fields and its benefits in the learning process. The results of this study found that - disregard the use of technology interactive learning could potentially improve the learning experience.
\end{abstract}

\section{Keywords: interactive learning; learning experience; computer-aided learning}

\section{INTRODUCTION}

To achieve a good learning achievement needs to make changes to the method of learning is monotonous. The use of improper learning models in the learning process will make learners tend to be passive during the lesson. Learners will be silent, listen and record the learning material provided by the teacher. To overcome the problems that occur, teachers need to try to implement new learning strategies. Learning strategy in question is an interactive learning strategy. The interactive creative learning is a process of creating meanings regarding the new information and the previous knowledge, of the transformation of cognitive structures of the student, a consequence of the incorporation of new acquisitions (knowledge, skills, and abilities), through the engagement of the intellectual and psychomotor efforts for building knowledge [1]. Interactive learning is increasingly used in the world of education with the aim to facilitate learning. Game based interactive learning and simulations bring a positive influence on student learning [2].

Literature underlines the importance of interactive learning in learners' improvement. Implementing an interactive learning strategy for children aged three to eight using dog robot (AIBO) can help improve understanding to distinguish the world of fantasy and reality [3]. An interactive learning strategy can be an effective tool for teaching social sciences to primary school students because the basic concept is easier so that topics can be understood and help students put social facts into structured schemes [4]. An interactive learning strategy is used to nurture learners to think critically, strategies for implementing active-participatory methods, methods of 
stimulating student creativity, multiple intelligence activation methods. Strategies based on modern methods of learning provide an opportunity to manifest the relationship between knowledge, information transfer, conclusions, but cognitive stimulation of independence in learning and activation of students' self-confidence [5].

Notwithstanding the vast literature on efforts to improve learning achievement of learners with interactive learning strategies, there seems likely a lack of explanation on how to improve learning achievement with interactive learning strategies would learners' learning achievement. This condition would likely leave practitioners and academic without clear guidance on how to operationalize the how to improve student achievement in real life. This review examines the published works in twenty established journals in education. A systematic literature review procedure was conducted upon twenty published between 2009 and 2016. Also, to obtain a granular elaboration about the matter, a framework to operationalize the efforts to improve students' learning achievement with interactive learning strategies in education is suggested. Based on the literature review that the author has read, only a few discuss the specific interactive learning strategy. Most of the existing literature studies discuss only games for education, and no one has discussed efforts to improve learning achievement. In this study of the literature, the authors want to raise the topic of efforts to improve learning achievement of learners with interactive learning strategies.

The rest of the paper is structured as follows: In the next section, the strategy of conducting the review of the literature is elaborated. The findings extracted from the review of the literature are suggested in the third section. The discussion upon the finding and the proposed strategies on the efforts to improve students' learning achievement with interactive learning strategies are proposed in the next section. In the final section, the paper is concluded.

\section{METHOD}

The review of the literature was conducted according to the Systematic Literature Review framework [6]. The review was done systematically upon dozens of articles in the Journal of Interactive Learning Research and the Procedia of the Social Behavioral Science. The distribution of papers in the publication outlets is depicted in Figure 1.

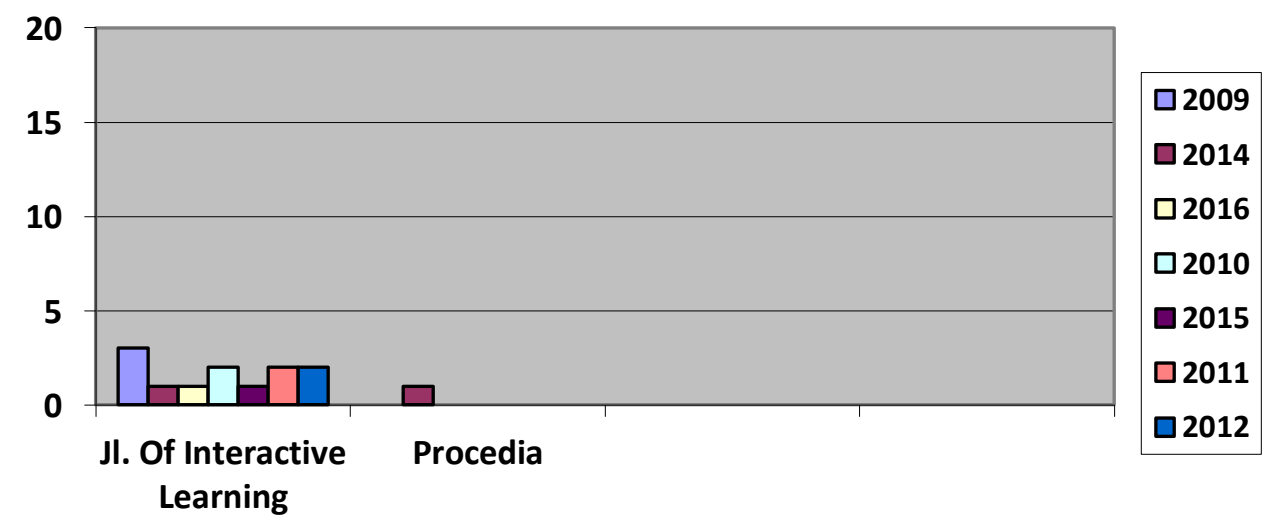

Figure 1. Distribution of reviewed papers 
The review search specifically papers published between 2009 and 2012 in that publication above outlets. The search utilized interactive learning the specific keyword returned a limited number of papers. The papers were examined for the insightful content relevant to the review objectives. The conceptual knowledge, then, teased out to build a new understanding of how interactive learning contributes to education.

\section{INTERACTIVE LEARNING}

Interactive learning is a learning activity that comprises various types of learning including game-based learning [7], designing a web, concept map [8], multimedia based learning [9], and robotics [10]. Through interactive learning, it is expected that individuals learn actively and able to permanently reorganize and restructure his achievements in a systemic order [1].

Outstanding education organizations around the world pay serious attention to the pedagogical aspects of interactive learning to improve the learning experience. Open University Hagen Germany, for example, conducted the Educational Computer Games and Learning: The Relationship between Design, Cognitive Load, Emotions, and Outcomes. In the study, students were asked to design educational computer games. Students delved into how the design of games interacts with cognitive activities and emotions and providing some implications adapting complex learning environments to the level of expertise of learners. It was expected that game designers would be able to identify which of the features are promising and expectedly save valuable time and money and improve the end product. The results of the study stated that the motivation and skills of learners in learning activities are increased [11].

Another research on the impact of multimedia instructional tool to student's motivation was conducted in the USA. The participants include 381 students in an introductory computer applications course. Interactive multi-media activities put the user in charge of the delivery of their educational materials. Multimedia instructional tools (mmIT) were created at the same time with the development of multimedia in accord to the structure of instructional design processes. Motivation and learning strategies were evaluated using the Motivated Strategies for Learning Questionnaire (SQL). Multimedia instructional tools (MIT) have been identified as an effective and economical instructional material. It was concluded that mats are effectively increasing student knowledge and positively impact motivation and learning strategies [12].

Research carried out at the IBM T. J. Watson Research Center, USA examined the representation of knowledge by outlining the knowledge in the concept map. A concept map is used to graphically represent knowledge of a particular domain. As a knowledge representation tool, users attempt to map representational mechanisms isomorphic to users' cognitive representations. The study outcomes suggested that concept maps help improve student comprehension and enhance learning [8].

A study introducing the use of a humanoid robot as an interlocutor in a foreign language learning was conducted in Singapore [10]. The English for a Foreign Language (EFL) class was provided for elementary students to increase children's motivation to learn English. It was designed to be an interactive language classroom involving the hardware arrangement, software design, and the interactive instruction process between teacher, students, and the robot. The setting was intended to create an interactive environment for teaching (and learning) in a relaxed a commanding dialogue 
practice activities for under-age students. The environment allowed teachers to concentrate more on helping students improve their listening comprehension and revise their pronunciation in the class. It was reported that ninety-five percent of the students enjoyed the English class more as a result of their teacher communicating through a robot. The children also actively participating in response to the guidance they received from the robot.

\section{DISCUSSION}

This paper contributes to the literature by amassing the knowledge on interactive learning reported in empirical publication outlets. Despite interactive learning is not a novel concept in the educational arena, an overarching writing on how interactive learning influence student's learning experience is currently under-explored. The limited number of published paper in interactive learning, we argue, may not be solely due to the lack of researcher's interest over interactive learning nor has the trend of interactive learning been faded. Apart from the effort to accumulate relevant papers in the journals, interactive learning may come up in other terms such as game- based learning, hands on learning, collaborative learning, and so on. Future review on interactive learning, therefore, could be improved by extending keywords applied in the search. The review on interactive learning papers indicates a promising insight into the extent of interactive learning to improve the learning experience. How interactive learning may influence learning was the underlying question of the study. The summary of the systematic review is summarized in the following.

Interactive learning stimulates student's critical thinking [1]. Students' level of awareness will be increased while they are taking part in an interactive learning delivered classroom. The engagement would likely encourage them to be more responsible with their learning. Interactive learning tends to kill boredom in learning [11]. The recent development of communication and digital media created an exciting world for children to grow up with. Digital technology enables children to play, express themselves, learn and communicate beyond their ancestor's experience. Interactive Learning creates engaging and immersive learning experiences [2]. Educational games are computer supported software that attractively engages learners for its interactivity. Through the use of characteristics of video and computer game, they could be designed for delivering specified learning goals, outcomes and experiences. Interactive Learning creates an interactive environment with linked physical artefacts and computer-based instructional elements [13]. The development of augmented reality technology enables learner consciously comprehend a reality that was artificially built. The interactivity is developed by embedding virtual world in a real environment. The examination into a broader context, Interactive Learning facilitates collaboration learning technique that potentially enhances the learning experience. Collaboration occurs when individuals interact one another and exercise, verify, solidify, and improve mental models through both discussion and information sharing. When collaboration works well, the virtual classroom model of interaction leads to greater communication among members of a learning group [14]. 


\section{CONCLUSION}

The passive nature of students in conventional learning environment needs to be resolved using un-conventional efforts. Teachers require a learning strategy to stimulate students to be more active. Learning strategy in question is the interactive learning. The review over a dozen of articles in the outstanding publication outlets reveals the application of interactive learning in an education field. A specific discussion, however, needs to be constructed upon the published works of scholars to enhance the significance of interactive learning to the learning experience. Four strategies have been teased out from the reviewed papers to shed light on the influence of interactive learning to the learning experience. The number of relevant papers being reviewed, however, limited the possibility of this study to generate a broader understanding of the topic. Since Interactive Learning may come up in other terms such as game-based learning, hands on learning, collaborative learning, such study could be improved in the future by extending keywords adopted in the search.

\section{REFERENCES}

[1] C. L. Oprea, "Interactive and Creative Learning of the Adults," Procedia - Soc. Behav. Sci., vol.142, pp. 493-498, 2014.

[2] S. Warren, M. Dondlinger, R. Stein, and S. Barab, "Educational game as a supplemental learning tool: Benefits, challenges, and tensions arising from use in an elementary school classroom," J. Interact. Learn. Res., vol. 20, no. 4, pp. 487-505, 2009.

[3] A. Francis and P. Mishra, "Is AIBO Real ? Understanding Children' s Beliefs About and Behavioral Interactions with,” Jl. Interact. Learn. Res., vol. 20, no. 4, pp. 405-422, 2009.

[4] F. Ceresia, "Interactive Learning Environments (ILEs) as Effective Tools for Teaching Social Sciences," Procedia - Soc. Behav. Sci., vol. 217, pp. 512-521, 2016. [5] R. Lile and G. Kelemen, "Results of Researches on Strategies of Teaching/Learning/Assessment Based on Interactive Learning Methods," Procedia - Soc. Behav. Sci., vol. 163, pp. 120-124, 2014.

[6] C. Okoli and K. Schabram, "Working Papers on Information Systems A Guide to Conducting a Systematic Literature Review of Information Systems Research," vol. 10, no. 2010.

[7] S. Weppel, M. Bishop, and H. Munoz-Avila, "The Design of Scaffolding in Game-based Learning: A Formative Evaluation,” J. Interact. Learn. Res., vol. 23, no. 4, pp. 361-392, 2012.

[8] K. Koury et al., "Case-based Instruction in Different Delivery Contexts: The Impact of Time in Cases," J. Interact. Learn. Res., vol. 20, no. 4, pp. 445-467, 2009. [9] T. Yuen and M. Liu, “A cognitive model of how interactive multimedia authoring facilitates conceptual understanding of object-oriented programming in novices," J. Interact. Learn. Res., vol. 22, pp. 329-356, 2011.

[10] C.-W. Chang and G.-D. Chen, "Using a humanoid robot to develop a dialogue-based interactive learning environment for elementary foreign language classrooms," J. Interact. Learn. Res., vol. 21, no. 2, pp. 215-235, 2010.

[11] C. Schrader and T. Bastiaens, "Computer Games and Learning: The Relationship between Design, Gameplay and Outcomes," J. Interact. Learn. Res., vol. 23, no. 3, pp. 251-271, 2012.

[12] D. L. Chapman and S. Wang, "Multimedia Instructional Tools and Student Learning in a Computer Applications Course," Int. J. Inf. Commun. Technol. Educ., vol. 11, no. 2, pp. 57-67, 2015.

[13] B. S. Parton, R. Hancock, and M. Mihir, "Physical World Hyperlinking: Can Computer-based Instruction in a K-6 Educational Setting be Easily Accessed through Tangible Tagged Objects," J. Interact. Learn. Res., vol. 21, no. 2, p. 257, 2010. 
[14] R. J. Ocker and G. J. Yaverbaum, "Collaborative learning environments Exploring student attitudes and satisfaction in face-to-face and asynchronous computer conferencing settings," Int. J. Interact. Learn. Res., vol. 12, no. 4, pp. 427-448, 2001. 